\title{
CORPORATIVISMO EN EL AREA DEL BIENESTAR. EL CASO DE LA ORGANIZACION NACIONAL DE CIEGOS
}

\author{
Roberto Garvía Soto
}

Universidad Carlos III de Madrid

La literatura sobre los grupos de interés ha subrayado repetidamente que es mucho más probable que los acuerdos de tipo corporatista tengan lugar antes en la esfera de la producción que en la esfera del consumo. En la primera, y con la intención de promover intereses opuestos, empresarios y trabajadores pueden recurrir a la acción colectiva e iniciar un proceso institucional que, eventualmente, garantice a sus respectivas organizaciones un monopolio de representación y cierto grado de participación en la gestión de las relaciones industriales y en la toma de decisiones macroeconómicas. Este proceso institucional no puede tener lugar sin la intervención, más o menos complaciente, del Estado, que persigue con ella garantizar y asegurar el control, predicibilidad y autorregulación de las demandas de empresarios y trabajadores, bajo la consideración que la ausencia de tal intervención puede terminar afectando críticamente ya la situación relativa del país en la comunidad internacional, ya la misma gobernabilidad del país.

Por el contrario, la probabilidad de que acuerdos de tipo corporatista tengan lugar en la esfera del consumo es mucho menor. Para explicar esto, la literatura sobre grupos de interés ha ofrecido dos razones. En primer lugar, mientras que en la esfera de la producción existe una división de intereses que empuja a las partes en conflicto (empresarios y trabajadores) a organizarse y movilizarse, la falta de tal cleavage en la esfera del consumo hace que el proceso de agregación de intereses sea un fenómeno mucho menos común. En segundo 
lugar, en la medida en que la posición relativa del país y su gobernabilidad no quedan afectadas por el modo en que los intereses en la esfera del consumo estén organizados, el Estado tiene menos incentivos para intervenir en el sistema de representación de intereses y, así, en promover acuerdos de tipo corporatista.

Esto explica por qué la literatura sobre los grupos de interés ha «descubierto" acuerdos corporatistas en el área de las políticas económicas y de las relaciones industriales (esto es, en la esfera de la producción), pero no en el área del bienestar (que pertenece, típicamente, a la esfera del consumo). Aquí los consumidores de programas de bienestar mantienen generalmente una relación individualizada con las agencias del Estado que gestionan estos programas con lo que las posibilidades de crear acuerdos corporatistas son casi nulas. Si éste no es el caso, y los consumidores de bienestar llegan a crear organizaciones de interés, estas organizaciones parecen condenadas a operar en un escenario pluralista, compitiendo unas con otras por recursos de bienestar que siempre son escasos. Puede ocurrir, ciertamente, que surja un acuerdo corporatista en el área del bienestar. Esto tendrá lugar cuando determinados grupos profesionales con intereses en este área (por ejemplo, los médicos) consiguen participar en el proceso de decisiones y en la implementación de políticas de bienestar (Cawson, 1982).

En resumen, la literatura ha subrayado que los acuerdos corporatistas difícilmente tienen lugar en las políticas del bienestar. Si, a pesar de todo, un acuerdo de este tipo surge en el ámbito de estas políticas, lo hará desde el lado de la producción (en este caso, promovido por grupos profesionales que proveen bienestar), pero no desde el lado del consumo, ya que los consumidores de bienestar bien carecen de organizaciones de interés, o bien, en caso contrario, estas organizaciones operan en el marco de un sistema plural de representación de intereses.

Este artículo ofrece evidencia empírica que debe servir para cualificar las predicciones de la literatura sobre el corporatismo. En concreto, se va a estudiar aquí el funcionamiento de un acuerdo corporatista en el área del bienestar, promovido no por grupos profesionales, sino por consumidores de bienestar. Este acuerdo tuvo su origen en plena Guerra Civil, cuando el gobierno de Franco, influido por el corporativismo de la Italia fascista, y presionado por líderes de organizaciones locales de ciegos, decidió crear la Organización Nacional de Ciegos (a partir de ahora, ONCE); una organización que monopolizaría la representación de intereses de los ciegos y que disfrutaría del privilegio de explotar una lotería (el cupón pro-ciegos), que serviría para recaudar los recursos necesarios para prestar todo tipo de servicios de bienestar para los ciegos.

El caso de los ciegos españoles no contradice por completo la literatura corporatista, ya que la emergencia de la ONCE no tuvo lugar bajo un régimen democrático, sino bajo un régimen empeñado en llevar adelante un proyecto político llamado retrospectivamente "corporatismo estatal» (Schmitter, 1979) 
o «autoritario» (Lehmbruch, 1977). Sin embargo, al contrario que otras organizaciones o acuerdos corporatistas, la ONCE no se desmanteló con la transición a la democracia. De este modo, el caso de los ciegos españoles ofrece la oportunidad de estudiar el funcionamiento de un acuerdo corporatista en el área del bienestar bajo un régimen autoritario y un régimen democrático.

El análisis de este acuerdo mostrará que, al contrario de los acuerdos corporatistas en el área de las relaciones industriales, el corporatismo en el área de bienestar puede ser extraordinariamente estable. Se sugiere aquí que esta estabilidad se debe a la especial relación de interdependencia en la que el Estado y la organización proveedora de servicios de bienestar están envueltos. Con respecto a la organización, desde el momento en que ésta monopoliza la provisión de unos servicios que son críticos para un segmento de la población, el Estado (ya sea autoritario o democrático) dependerá de la organización (siempre que considere que es su deber garantizar el bienestar de ese segmento de la población). Al mismo tiempo, la organización proveedora depende del Estado, en cuanto que éste puede revalidar o retirar el status que concedió a la organización como monopolizadora de servicios. Esta relación de interdependencia limita y determina el rango de demandas que cada una de las dos partes puede presentar, garantizando así un alto grado de predicibilidad y estabilidad al acuerdo corporatista.

Predicibilidad y estabilidad, sin embargo, no implica inmutabilidad. Como este artículo mostrará, los acuerdos corporatistas pueden precipitar cambios muy significativos en el área en la que operan. En concreto, se mostrará aquí cómo un acuerdo corporatista de alcance limitado en el área de las políticas en favor de los minusválidos, se extendió sobre todo este área y transformó lo que era un sistema plural de representación de intereses en un sistema corporatista.

En resumen, este artículo mostrará, en primer lugar, que, al contrario de lo que la literatura anticipa, pueden tener lugar acuerdos corporatistas no inducidos por grupos profesionales en el área del bienestar; y, en segundo lugar, que los acuerdos corporatistas en este área pueden verse sometidos a una lógica expansiva. En la primera sección del artículo se analizará cómo los ciegos españoles consiguieron alcanzar un acuerdo privilegiado de tipo corporatista con el gobierno autoritario. Este acuerdo resultó en la creación de una nueva organización, la ONCE, a la que se garantizó un monopolio de representación y el privilegio de explotar una lotería, con la que los ciegos podrían asumir responsabilidades públicas. Con el fin de mantener esta situación privilegiada, la ONCE tuvo que anticiparse y sortear las críticas de otros grupos de minusválidos e interferir en la organización de los intereses de estos otros grupos. En la segunda sección se mostrará cómo la ONCE, como resultado de esta intervención, consiguió crear a mediados de los ochenta un nuevo sistema corporatista de representación de intereses y asumir nuevas responsabilidades públicas en el área de las minusvalías expandiendo, de esta forma, un acuerdo corporatista (que si inicialmente sólo iba a afectar a los ciegos, terminó afectando a toda la población minusválida). En la tercera sección se señalarán las características de 
este nuevo sistema de representación de intereses y de este nuevo acuerdo corporatista en el área de las minusvalías. Finalmente, en la última sección se repasarán los argumentos básicos del artículo.

Antes de seguir adelante, sin embargo, es necesario hacer unos breves comentarios sobre la ONCE. Esta organización monopoliza tanto la representación de intereses de los ciegos como la provisión de servicios en beneficio de los mismos. El rango de servicios que presta la organización a los ciegos españoles es en muchos casos superior al de otras organizaciones de ciegos de otros países más desarrollados que España. En concreto, respecto al empleo, la ONCE ha conseguido que la tasa de actividad de los ciegos españoles sea la más alta entre los países desarrollados. Además, y paradójicamente, la tasa de desempleo de los ciegos españoles es nula, o meramente estructural, mientras que la tasa de desempleo de los españoles no ciegos supera actualmente (mayo de 1994) el 20 por 100 de la población activa (Garvía, 1994). Este éxito en la política de empleo se debe tanto al privilegio de los ciegos de explotar su propio negocio de lotería como a la pasión del resto de los españoles por el juego. Y aquí, de nuevo, tiene lugar una situación atípica con respecto al resto de países desarrollados, pues España tiene, desde hace tiempo, el mayor mercado de loterías europeo ${ }^{1}$. En un suelo tan generoso para el negocio de las loterías, la ONCE consiguió en 1989 convertirse, por sus beneficios, en la decimosexta empresa más importante del país; y por el número de empleados, en la cuarta.

\section{EL PERIODO AUTORITARIO}

Contrariamente a otros grupos de los que hoy se llaman «minusválidos», los ciegos consiguieron crear una asociación nacional ya en $1924^{2}$. Formaban parte de esta asociación una pluralidad de organizaciones locales, algunas de las cuales explotaban, con la tolerancia de las autoridades locales, pequeñas loterías. Con la explotación de sus loterías, los ciegos de estas asociaciones locales consiguieron resolver dos problemas. En primer lugar, vendiendo lotería, los ciegos no tenían que recurrir a la mendicidad para garantizarse un mínimo de ingresos. En segundo lugar, con los recursos excedentes de la lotería, algunas organizaciones locales fueron capaces de crear programas de bienestar que el Estado no estaba en condiciones de financiar debido a la precariedad de las haciendas locales.

Sin embargo, no sólo los ciegos explotaban pequeñas loterías a principios

${ }^{1}$ En 1991, el gasto per cápita en loterías en España fue 108 ECUs. En segundo lugar se situaron la antigua RFA y Grecia, con un gasto estimado de 74 ECUs. Datos en Gambling in the Single Market.

${ }^{2}$ Los ciegos ya estaban organizados desde el siglo XIV en gremios y hermandades específicas de ciegos. Estas organizaciones de ayuda mutua consiguieron mantenerse a flote durante el siglo XIX, en el que estos gremios fueron oficialmente desarticulados, de modo que los ciegos seguían disponiendo de una red de organizaciones locales a la entrada del siglo XX. 
del siglo XX. Otros grupos de minusválidos y de ancianos también se dedicaban a la explotación ilegal del juego. Además, en no pocos lugares, y debido a la mala situación de las haciendas locales, algunos organismos locales de beneficencia también promovían sus propias loterías ilegales. La lotería de los ciegos, sin embargo, era la mejor situada en este mercado ilegal, ya que estaba respaldada por una organización nacional de cierto prestigio que, al mismo tiempo, mostró ser un grupo de presión relativamente exitoso.

Esta organización se transformó en la Organización Nacional de Ciegos en 1938, esto es, en plena Guerra Civil. Los ciegos obtuvieron del gobierno franquista la legalización de su lotería, argumentando, muy persuasivamente, que el nuevo Estado, envuelto en una Guerra Civil, no podría satisfacer las necesidades de los ciegos civiles y de los ciegos veteranos de guerra. De esta forma, el siguiente acuerdo corporatista emergió en aquel año: la ONCE monopolizaría la representación de intereses de los ciegos y, con los recursos de su lotería, asumiría responsabilidades públicas en favor de los ciegos, como la gestión y financiación de pensiones para los ancianos, de programas de formación profesional para los jóvenes, y programas de educación especial para los niños ciegos. De acuerdo con la filosofía del estado autoritario, se convino que la ONCE estaría estrechamente supervisada por un órgano colegiado compuesto en su mayor parte por burócratas de la Dirección General de Beneficencia, entonces dependiente del Ministerio de Gobernación. Esto significaba que la ONCE carecería de toda autonomía de gestión. En la práctica, sin embargo, y durante la mayor parte del período franquista, la organización fue capaz de neutralizar la supervisión de la Dirección General de Beneficencia e, incluso, de ganarse el apoyo del Estado en contra de las demandas de otros grupos de minusválidos ${ }^{3}$.

Para poder cumplir con sus nuevas responsabilidades públicas, los ciegos debían evitar que otros grupos de minusválidos u otras organizaciones de beneficencia vendieran sus propias loterías. Así, una de las primeras ocupaciones de la ONCE fue presionar en el Ministerio de Gobernación contra las otras loterías, ilegales, pero toleradas por las autoridades locales, que competían con la lotería de los ciegos. La organización de ciegos tuvo éxito en sus

${ }^{3}$ El proceso por el cual una organización consigue cooptar la agencia del Estado encargada de controlarla y, así, beneficiarse de los poderes públicos asignados a esa agencia ha sido estudiado en otras ocasiones (Suleiman, 1987; Lowi, 1979). La lógica de este proceso es la siguiente: la agencia tiene, estatutariamente, una misión que cumplir y, para poder cumplir con esta misión, ha de ganarse la confianza de la organización que está bajo su tutela. Ha de ganarse esta confianza porque, muy posiblemente, los mecanismos de control de que la agencia dispone son rudimentarios, o la organización puede hacer que estos mecanismos sean insuficientes, ya que la organización realiza una labor en la que ella, y no la agencia estatal, es la experta. En otras palabras, puede ocurrir que no haya control posible sin la colaboración de la organización que se ha de controlar y, a cambio de su colaboración, la organización puede hacer que este control sea cada vez menos estricto. A largo plazo, la agencia no controla a la organización y ambas pueden terminar considerando que el papel de la primera no es el de controlar a la segunda, sino el de protegerla frente a cualquier otro control público. 
presiones, y los gobernadores civiles de las provincias afectadas recibieron órdenes para actuar en contra de estas otras organizaciones. Así, la mayoría de las organizaciones de minusválidos y ancianos que aún explotaban sus loterías después de la Guerra Civil fueron desmanteladas. En algunos casos, los miembros de estas asociaciones ingresaron en la ONCE, y, respecto a las organizaciones de beneficencia, en algunas ocasiones la ONCE tuvo que contribuir con pagos anuales para que dejaran de vender sus loterías. De esta forma, a finales de los años cuarenta, la ONCE consiguió el monopolio de las loterías benéficas: sólo los ciegos podían vender este tipo de lotería y competir con la lotería del Estado. Una vez conseguido este monopolio, la ONCE se amplió sus programas de bienestar. Se crearon entonces talleres protegidos para los ciegos, y aumentó la cuantía y calidad de otros beneficios, como las pensiones de jubilación, los servicios médicos, las compensaciones por enfermedad, etc.

Otros grupos de minusválidos no eran tan afortunados como los ciegos. Entre estos otros grupos los más aventajados eran los minusválidos físicos, a pesar de la escasez de programas sociales destinados a ellos. La mayoría de estos programas iban dirigidos a procurar la rehabilitación física de los minusválidos, pero no a procurarles un empleo o a garantizarles unos ingresos mínimos. No es de extrañar, entonces, que a finales de los cincuenta, esto es, al término del período más represivo del régimen franquista, surgieran pequeñas organizaciones locales e informales de minusválidos, orientadas a reclamar para sus miembros programas sociales similares a aquellos de los que los ciegos estaban disfrutando. Algunas de estas organizaciones, como cabe esperar, empezaron a explotar su propio negocio de lotería, que competía directamente con la lotería de los ciegos.

La ONCE empleó dos estrategias frente a esta amenaza. La primera es la clásica "divide y vencerás», o, en el lenguaje de la sociología de las organizaciones, boundary setting (Haldrich, 1973). Esta estrategia consistía en permitir el ingreso de algunos minusválidos en la ONCE, procurando de este modo dividir sus intereses dejando a unos dentro y a otros fuera de la organización de ciegos. Los que ingresaban en la organización pasaban inmediatamente a defender el privilegio de los ciegos, mientras que los que se quedaban a las puertas podían seguir criticándolo. Estas críticas, sin embargo, perdían gran parte de su fuerza, ya que permitiendo el ingreso de algunos minusválidos, la ONCE podía presumir de generosidad, manteniendo que era tan sensible al problema de los minusválidos como para permitir el ingreso de cierto número de ellos en su plantilla 5 .

${ }^{4}$ Sólo existían programas de empleo y pensiones de minusvalía para los excombatientes del bando nacional. Los programas de rehabilitación para los minusválidos civiles estaban gestionados por el Instituto Nacional de Reeducación de Inválidos (creado en 1933) o por el Patronato de Lucha contra la Invalidez (creado en 1949), en los que la Iglesia jugaba un papel fundamental.

5 En 1968, 2.844 vendedores de la ONCE eran minusválidos, una cifra que representa el 18 por 100 de la plantilla de la organización de ciegos. 
La segunda estrategia consistía en anticiparse a los minusválidos, crear una organización nacional que los "representara», y hacer que esta organización dependiera de la ONCE, con el fin de controlar sus demandas. Así, a instancias de la ONCE, la Dirección General de Beneficencia creó la ANIC (Asociación Nacional de Inválidos Civiles), en 1958. Dentro del espíritu corporatista de la España de Franco, la ANIC debería ser la única organización legal de los minusválidos, y monopolizar la representación de los intereses de los mismos, del mismo modo que la ONCE monopolizaba la representación de los intereses de los ciegos. La ANIC entonces cumplía dos funciones en la España autoritaria. La función manifiesta era la de procurar empleo a los minusválidos, algunos de los cuales, efectivamente, empezaron a trabajar como guardacoches en aparcamientos públicos o como vendedores callejeros de la lotería del Estado. La función latente, sin embargo, era la de evitar que los minusválidos censuraran los privilegios de los ciegos, y que promovieran loterías que compitieran con el cupón de los ciegos.

Esta estrategia funcionó satisfactoriamente durante los primeros años de existencia de la ANIC, pero pronto la Dirección General de Beneficencia aprendió a sacar provecho de ella. En concreto, esta Dirección General necesitaba recursos tanto para garantizar el funcionamiento de la ANIC como para financiar los programas del FNAS, y comenzó a solicitar a la ONCE más y más ayudas, sugiriendo a la ONCE que, en caso de no prestarse a colaborar, la Dirección no podría garantizar el control de las demandas de los minusválidos de la ANIC, así como la posibilidad de que organizaciones rivales de minusválidos comenzaran a explotar sus propias loterías ${ }^{6}$. Este tipo de peticiones no agradaba a la ONCE. La organización de ciegos estaba dispuesta a pagar la aquiescencia de los minusválidos físicos, pero quería poner el precio ella misma, y no que se lo impusiera la Dirección General de Beneficencia. La experiencia de la ANIC enseñó a la ONCE que para controlar las demandas de los minusválidos físicos era necesario que la organización que los representara dependiera directamente de la ONCE, y no de ninguna agencia del Estado.

En resumen, en el período franquista los ciegos fueron capaces de controlar las demandas de los minusválidos. Este control, sin embargo, resultó más difícil de mantener con el transcurso de los años. En primer lugar, ejercer ese control era más caro año tras año, en la medida en que el Estado, que iba ampliando su cobertura a otros grupos de minusválidos, se había acostumbrado a solicitar a la ONCE contribuciones cada vez más cuantiosas. En segundo lugar, las posibilidades de controlar las demandas de los minusválidos eran progresivamente menores, ya que la relativa apertura y liberalización del régimen franquista a finales de los sesenta permitió que se creara una amplia red de organizaciones para minusválidos que funcionaba al margen de la ANIC.

${ }^{6}$ El FNAS era el Fondo Nacional de Asistencia Social, creado en 1960 con el objetivo de apoyar y supervisar programas en favor de los minusválidos psíquicos, de los huérfanos y de los ancianos.

${ }^{7}$ A la liberalización económica, que comenzó con la entrada de los tecnócratas en el gobier- 


\section{EL PERIODO DEMOCRATICO}

Durante el período de transición a la democracia, las organizaciones para minusválidos terminaron confluyendo con nuevas organizaciones de minusválidos, creadas después de 1975, generándose de este modo un nuevo entramado asociativo que tuvo como consecuencia la obsolescencia y desmantelamiento oficial de la ANIC. Sin embargo, por varias razones, los minusválidos físicos tardaron en crear una nueva asociación nacional que reemplazara a la antigua ANIC. En primer lugar, a los problemas asociados con la lógica de la acción colectiva (Olson, 1965) había que añadir las dificultades de asociarse, precisamente, a través de un estigma ${ }^{8}$. En segundo lugar, el proceso de la agregación de las demandas de los minusválidos se vio dificultado por el hecho de que las nuevas organizaciones representaban diferentes colectivos con diferentes demandas (como las de los afectados por polio, parálisis progresiva, parálisis cerebral, etc.). En tercer lugar, algunas de las demandas más importantes sólo podían ser satisfechas por las administraciones locales (como la supresión de las barreras arquitectónicas), de modo que no pocos líderes de organizaciones locales consideraban que sería una pérdida de tiempo y recursos esforzarse en la creación de una organización nacional, ya que, mantenían, el nuevo régimen autonómico lo haría ineficiente. Por último, y más importante, los minusválidos físicos estaban divididos con respecto a la estrategia a seguir. Por un lado, estaban aquellos que pensaban que si sus problemas no habían sido resueltos, esto no era debido a su déficit organizativo, o a la naturaleza, compleja, de sus problemas, sino a la falta de sensibilidad del régimen anterior. Según su punto de vista, con un ejercicio de denuncia permanente, por medio de sentadas, huelgas de hambre o manifestaciones, el nuevo Estado democrático, por su propia naturaleza y casi automáticamente, no tardaría en resolver sus problemas. Con ello cuestionaban la oportunidad de crear una organización nacional, que terminaría burocratizando el movimiento y, así, mermando su carácter reivindicativo, participativo y democrático.

Por otro lado, estaban aquellos que querían transformar este movimiento social en una organización formal, que priorizara e hiciera coherentes las distintas demandas de los minusválidos, y sirviera de interlocutor válido frente a la administración con el fin de resolver los problemas por vía de la negociación y el consenso. Esta organización se creó en 1977. La CEMFE (Coordinadora Estatal de Minusválidos Físicos), sin embargo, era una organización excesiva-

no de 1957 , le acompañaron otras medidas que suponen una apertura política del régimen, como la Ley de Convenios Colectivos de 1958, la Ley de Prensa de 1966 o la Ley de Asociaciones de 1966, al amparo de la cual los padres con hijos minusválidos comenzaron a organizarse (Jordana de Pozas, 1967). Estas organizaciones de padres pudieron funcionar al margen de la ANIC, porque eran organizaciones para, y no de, minusválidos.

${ }^{8}$ Sobre el déficit organizativo de las poblaciones estigmatizadas, véanse Scotch (1988) y Hahn (1988). 
mente democrática, lenta en su proceso de toma de decisiones $\mathrm{y}$, en no pocas ocasiones, al borde de la ruptura9 .

Los problemas internos de la CEMFE no explican por completo la escasez de resultados. La crisis económica de finales de los años setenta y principios de los ochenta no facilitó que los minusválidos vieran satisfechas sus demandas. Estas eran, fundamentalmente, tres. Con respecto a la supresión de las barreras arquitectónicas, la administración central aprobó un Decreto en 1983 que preveía la eliminación de estas barreras en lugares públicos y edificios oficiales. Sin embargo, este Decreto no se aplicó, dado que no se habilitaron fondos para ponerlo en práctica. De modo semejante, y con respecto a las prestaciones no contributivas, la Ley de Integración Social del Minusválido (LISMI) prometía una regulación generosa de ingresos mínimos. Resultó, sin embargo, y según las provisiones de un decreto de desarrollo de la LISMI, que sólo el 20 por 100 de los minusválidos tenían derecho a algún tipo de prestación, que, además, no alcanzaba a la mitad del salario mínimo interprofesional. Por último, y con respecto al empleo, la LISMI reproducía las provisiones de un viejo Decreto de 1970, que contemplaba una reserva de empleo del 2 por 100 en las empresas con más de 50 empleados. Esta provisión tampoco se ejecutó, ya que significaba introducir nuevas regulaciones en el mercado de trabajo en unos momentos en que la administración y empresarios (contra la oposición de los sindicatos) se estaban esforzando en flexibilizar el mercado de trabajo. (El hecho de que no se aplicaran estas medidas de discriminación positiva, y así, de que el mercado de trabajo no se viera afectado, favoreció que los sindicatos se abstuvieran de intervenir en el área política de las minusvalías.) Como resultado de todo esto, según cifras de 1986, sólo el 12 por 100 de los minusválidos en edad laboral estaba empleado (INSERSO, 1989, vol. 1, 156).

De esta manera, no es de extrañar que un buen número de minusválidos físicos ingresaran en una nueva organización que satisfacía su demanda más importante: un puesto de trabajo. Esta organización era propiamente una empresa, PRODIECU, cuya actividad consistía en explotar una lotería ilegal, y que contrataba minusválidos a fin de justificar su actividad. PRODIECU se creó en 1985, en Cataluña, y rápidamente se extendió por todo el país. Con el fin de extender sus actividades en todo el territorio nacional, PRODIECU creó una organización títere, APEM (Asociación de Promoción de Empleo de Minusválidos), que disfrutaba dentro de PRODIECU de un sistema de closed shop, de modo que los minusválidos que quisieran trabajar para PRODIECU debían ser miembros de APEM. PRODIECU, sin embargo, no consiguió gobernar APEM a medida de sus deseos, y pronto los líderes de APEM intentaron controlar la organización matriz. Su propósito era crear una organización de minusválidos que explotara su propia lotería; esto es, una réplica de la ONCE en versión minusválidos físicos. Los líderes de APEM fracasaron en su

9 Un estudio del movimiento social de los minusválidos físicos en este período, Díaz Casanova (1985). 
intento, y PRODIECU se vio en la necesidad de crear una nueva organización títere: COEM (Confederación Española de Minusválidos). COEM mostró ser más fiel a PRODIECU. También presionó ante la opinión pública en favor de la lotería de los minusválidos, pero, al contrario que APEM, los líderes de COEM mantenían que la organización de minusválidos debía subcontratar su lotería a una empresa privada (esto es, a PRODIECU). En cualquier caso, y al margen de esta sopa de letras, el hecho es que la ONCE pudo comprobar que se había hecho realidad su pesadilla más temida: siete mil minusválidos físicos estaban vendiendo una lotería que competía directamente con el cupón de los ciegos. Los minusválidos, además, y al margen de las rivalidades entre APEM y COEM, estaban argumentando cotidianamente, por el hecho de vender su lotería en todas las provincias del país, que frente a un problema similar (el problema de encontrar trabajo en una economía de mercado), ellos merecían un trato similar (la oportunidad de explotar su propia lotería tal como los ciegos venían explotando la suya desde 1938).

Pero no sólo la ONCE estaba amenazada por la existencia de PRODIECU. El pluralismo asociativo que surgió alrededor de PRODIECU también perjudicaba la imagen que la CEMFE quería ofrecer de sí misma como representante única de los intereses de los minusválidos físicos. En contra de APEM y COEM, sin embargo, la CEMFE optó por no apoyar la idea de la lotería de los minusválidos. Ciertamente, esta decisión colocaba a la CEMFE en una situación difícil frente a su base natural, pero, al mismo tiempo, esta decisión le permitía presentarse frente a las administraciones como la vieja y dialogante organización nacional de minusválidos que, sin recurrir a actividades al margen de la legalidad, pretendía resolver los problemas de los minusválidos vía concertación y entendimiento. Con ello buscaba conseguir lo que desde hacía mucho tiempo deseaba; esto es, un status público como la única interlocutora de los minusválidos. Al respecto, la ONCE no deseaba otra cosa que apoyar a la CEMFE: la única organización nacional de minusválidos que no reclamaba su propia lotería. De esta manera, los intereses de la CEMFE y la ONCE convergieron en contra de PRODIECU, de modo que las dos organizaciones pudieron alcanzar varios acuerdos de colaboración. Así, en octubre de 1985, después de denunciar pública y repetidamente a PRODIECU, la CEMFE empezó a recibir apoyo económico por parte de la ONCE. Con estas ayudas, la CEMFE podía ofrecer a sus miembros incentivos selectivos (como la participación en programas de formación profesional), que le servían para fortalecerse organizativamente vis-à-vis otras organizaciones de minusválidos. Además, la ONCE prometió contratar a mil nuevos vendedores minusválidos, y ofreció a la CEMFE la posibilidad de participar en el proceso de selección del nuevo personal. De esta manera la CEMFE estaba en condiciones de ofrecer puestos de trabajo permanentes, bien retribuidos y, al contrario que otras organizaciones de minusválidos, completamente legales. Gracias a este tipo de acuerdos emergió una nueva CEMFE, cuya viabilidad como organización, sin embargo, dependía enteramente de la generosidad de la ONCE. Para resumir, la ONCE 
no hacía otra cosa que aplicar una vez más las dos mismas estrategias que ya puso en práctica durante la etapa autoritaria. En primer lugar, abriendo sus puertas a un determinado número de minusválidos, la ONCE intentaba dividir sus intereses. En segundo lugar, la ONCE buscaba promover y cooptar una organización de interés de los minusválidos físicos que no pusiera en peligro el privilegio que consiguió en 1938, según el cual sólo los ciegos podían explotar una lotería. Sin embargo, esa organización estaba muy lejos de monopolizar la representación de los intereses de los minusválidos físicos, ya que más de 7.000 minusválidos, desatendiendo las amonestaciones de la CEMFE, seguían vendiendo la lotería de PRODIECU.

Para mantener su privilegio no era suficiente, sin embargo, reforzar la CEMFE; era necesario que el Estado desmantelara PRODIECU. El Estado, por su parte, compartía este interés. En primer lugar, la lotería de los minusválidos competía con las loterías del Estado, reduciendo, consiguientemente, los ingresos públicos. En segundo lugar, la lotería de los minusválidos físicos situaba al Estado en una situación embarazosa, ya que esta lotería exponía abiertamente su incapacidad para resolver el problema del desempleo entre los minusválidos. Por esta misma razón, sin embargo, y aunque las actividades de PRODIECU eran ilegales, el Estado no podía desmantelar automáticamente esta organización, ya que esto significaba dejar sin empleo a más de 7.000 minusválidos. La escasa disposición de los miembros de la clase política a asumir los costes electorales del desmantelamiento de PRODIECU favoreció la extensión de esta organización por todo el territorio nacional y el atrincheramiento comercial de la lotería de los minusválidos en el mercado nacional de las loterías. La falta de decisión del Estado perjudicaba enormemente a la ONCE, que, con razón, temía que la opinión pública empezara a considerar como un hecho natural el que, al igual que los ciegos, los minusválidos tenían derecho a explotar su propia lotería ${ }^{10}$.

Ante las dificultades del Estado a la hora de actuar en contra de PRODIECU, la ONCE propuso su propia solución. La propuesta de la ONCE era la siguiente: la ONCE contrataría 7.000 minusválidos, el número estimado de vendedores de la lotería rival. A cambio, el Estado, liberado del coste político que supondría dejar sin empleo a este número de minusválidos, desmantelaría

${ }^{10}$ Durante los años en que los minusválidos vendieron su lotería, no se hicieron encuestas mínimamente fiables que sirvieran para mostrar el grado de aceptación de la opinión pública con respecto a esta lotería. La ONCE, sin embargo, tenía fuertes indicios para sospechar que el nivel de aceptación era alto. Uno de éstos hace referencia a un pretest publicitario, para el que se eligió el eslogan «Rechace imitaciones». Esto es lo que ocurrió en el ensayo del pretest, tras el que se descartó aquel eslogan: «En un principio [el eslogan era] "Rechace imitaciones", yo estuve presente en la realización de este pretest, que se llevó a cabo a través de unas dinámicas de grupo, orientadas, evidentemente. Pero la gente lo rechazaba, y, además, está en conexión con el eslogan. La gente rechazaba el eslogan y decía que la ONCE no tenía por qué decir eso, [porque] en cierto modo era una descalificación a nuestra competencia. Evidentemente se referían a PRODIECU» (ONCE, 1986: 53). 
PRODIECU. Sin embargo, para contratar a 7.000 nuevos trabajadores, la ONCE preveía una reforma sustancial de su lotería que, muy probablemente, reduciría significativamente la cuota de mercado de las loterías públicas. En resumen, la estrategia de la ONCE era la de combatir PRODIECU en el terreno político (y no en el del mercado), fortalecer la CEMFE con el fin de controlar las demandas futuras de los minusválidos, y hacer que el Estado pagara por todo ello.

El Estado rechazó la propuesta de la ONCE. Ciertamente, también era su deseo que PRODIECU desapareciera, pero no a costa de reducir los ingresos públicos. Antes de resignarse a esta reducción, el Estado quería comprobar si podía desmantelar la lotería ilegal ya a expensas de la ONCE, ya «gratis». Intentó lo primero a principios de 1986, cuando propuso a la ONCE que contratara a 7.000 minusválidos sin reformar su lotería. Como cabía esperar, la ONCE rechazó esa idea, que equivalía a proponer a los ciegos que redujeran sus ingresos y que los compartieran con los minusválidos. Ante esta contrapropuesta del Estado, los ciegos renovaron su anterior propuesta, cualificándola, sin embargo, muy significativamente. En concreto, en esta ocasión la ONCE proponía que si el Estado aceptaba su anterior fórmula, la ONCE dedicaría el 5 por 100 de los beneficios de su nueva lotería a la creación de un Fondo de Solidaridad con los Minusválidos. Con esta cualificación la ONCE sugería que la reducción de ingresos públicos que la nueva lotería de la ONCE iba a causar, podría compensarse con el ahorro que suponía la creación de aquel Fondo de Solidaridad, que colaboraría con las administraciones públicas en la gestión y financiación de programas a favor de los minusválidos. En pocas palabras, la ONCE estaba dispuesta a compartir gastos con el Estado para la desarticulación de la lotería de los minusválidos.

La respuesta del Estado a esta segunda propuesta fue, de nuevo, negativa, pues éste quería antes comprobar si podía desmantelar PRODIECU sin ningún tipo de coste. Así, en abril de 1986, cuatro ministerios (Justicia, Economía y Hacienda, Interior, Trabajo y Seguridad Social) redactaron un comunicado conjunto que fue ampliamente difundido en la prensa. Este comunicado era una mezcla de paternalismo y amonestaciones. En él se reconocían las difíciles condiciones de vida de los minusválidos físicos, que les habían empujado a ponerse en las manos de determinados individuos. Se hacía un repaso a las medidas de promoción de empleo llevadas adelante, y se prometía la ampliación de recursos para este fin. Finalmente, se les recordaba que estaban realizando una actividad ilegal, y se les advertía que se tomarían medidas contra la empresa que les había contratado sorprendiéndoles en su buena fe. Estas medidas, efectivamente, se tomaron. Se precintaron algunas sedes de PRODIECU y se decomisaron sus cupones. Los minusválidos, por su parte, se manifestaron en contra de estas medidas, y a los pocos días ya estaban vendiendo otra vez su lotería, porque consideraban que tenían tanto derecho como los ciegos a hacerlo. La acción del Estado, en fin, resultó patética, pues quedó de manifiesto la inutilidad de su 
poder regulador y admonitorio cuando, ante el temor de sufrir fuertes costes políticos, se muestra incapaz de utilizarlo ${ }^{11}$.

Este fracaso enfureció a la ONCE, que, finalmente, decidió llevar adelante la reforma de su cupón, la aprobara o no el Estado. La organización de ciegos consideraba que, de la misma forma que los minusválidos se habían situado al margen de la legalidad, los ciegos también tenían derecho a hacerlo. En otras palabras, la ONCE envió un ultimátum al Estado: o bien aceptaba su anterior propuesta, o bien debía enfrentarse a una situación aún más embarazosa ${ }^{12}$.

Este ultimátum asustó a ambas partes. En los círculos de la ONCE se empezó a recordar la intervención del Estado en RUMASA y, por parte del Estado, se temía que la ONCE llevara adelante su amenaza. Efectivamente, la ONCE la llevó adelante, de modo que en octubre de 1987 sacó a la venta el Cuponazo. A fin de evitar una situación embarazosa, el Estado aprobó una semana antes la reforma del Cuponazo, que aceptó como un hecho consumado. A finales de octubre desplegó las fuerzas policiales en lo que se llamó la Operación Boleto, que consistió en precintar las sedes de PRODIECU y urgir a sus vendedores a visitar las oficinas de la ONCE para solicitar un puesto de trabajo. Este fue el fin de PRODIECU.

Ni la ONCE ni el Estado, sin embargo, se ajustaron a los términos implícitos de su acuerdo. El Estado, con el fin de contrarrestar el Cuponazo, sacó a los pocos meses (febrero de 1988) una nueva modalidad de lotería (el Bonoloto) y, por su parte, la ONCE no contrató a los 7.000 minusválidos que prometió contratar ${ }^{13}$.

Llegados a este punto es necesario explicar por qué el Estado, antes que

${ }^{11}$ De nuevo, no es posible evaluar el estado de la opinión pública con respecto al tema de la lotería de los minusválidos, pero con ocasión de esta actuación del Estado no faltaron en la prensa declaraciones de este tipo: "Tengo un hijo disminuido psíquico de 21 años que empieza a vivir dignamente gracias a la venta de este cupón (...) Por ello, como padre, quiero decirle bien alto a la Administración que no desmonte PRODIECU, que, al fin y al cabo, emplea a miles de minusválidos en toda España. En cambio sí debería dedicarse a vigilar otras especulaciones que se dan. Añadiría, además, que cuando intenten hundir alguna actividad, tengan prevista otra mejor. Ahora, pretenden dejar en la más absoluta indefensión a un colectivo tremendamente desprotegido" (El Periódico, 7 de mayo de 1987). Sobre las «otras especulaciones que se dan", véase la siguiente nota.

12 Al margen del asunto PRODIECU, la situación del mercado del juego ya era bastante embarazosa para las administraciones. Los desacuerdos entre la Administración central y las autonómicas sobre la regulación del mercado del juego en las autonomías tuvo como consecuencia que este sector careciera de una regulación eficaz, lo que dio pie a no pocos escándalos políticos centrados alrededor del tema del juego y de la financiación de los partidos políticos. Para mencionar unos pocos: el caso Barreiro, en Galicia (que salió a la luz en noviembre de 1986); el caso de las loterías instantáneas, en el País Vasco (diciembre de 1986); el caso Patxot, en Cataluña, que continuó en lo que se llamó el Lottogate (en 1987 y 1988); el escándalo de las administraciones de lotería concedidas a militantes del partido socialista (primavera y verano de 1986). Sobre el déficit regulativo del mercado del juego, Guirao (1985) y Garvía (1992: 196-203).

${ }^{13}$ La promesa de incorporar a 7.000 nuevos minusválidos se hizo en junio de 1987, pero desde diciembre de 1986 hasta diciembre de 1990 el número de minusválidos en plantilla sólo aumentó en 3.763 vendedores. Datos en Memoria Económica 89-90, p. 32. 
proceder en contra de la ONCE, decidió aceptar sus términos. En efecto, el Estado podía haber decidido retirar a los ciegos el privilegio que se les concedió en 1938, y proveer bienestar de forma directa, del mismo modo que otros minusválidos recibían programas de bienestar. Sin embargo, por muy legítima que esta decisión pudiera parecer en el marco de la nueva España democrática y liberal, por razones prácticas, esto no era viable. En términos básicos, la ONCE y el Estado estaban (y están) envueltos en una relación de interdependencia. Por un lado, el Estado dependía de la organización en cuanto que ésta monopolizaba la provisión de servicios críticos para sus miembros; pero, por otro lado, la ONCE dependía del Estado en cuanto que éste podía refrendar o retirar el status público de la ONCE y el privilegio de explotar su lotería. Esta relación de interdependencia había estado operando sin apenas contratiempos durante casi cuarenta años. El asunto PRODIECU, sin embargo, alteró este equilibrio de poder entre la ONCE y el Estado, ya que, como éste descubrió, la solución al problema de la lotería de los minusválidos estaba en manos de la ONCE, que era quien podía emplear a los vendedores de PRODIECU. Esta dependencia adicional del Estado con respecto a la ONCE impidió que el primero evaluara la posibilidad de desmantelar la ONCE, de la que no sólo dependía el bienestar de los ciegos, sino también la posibilidad de desmantelar PRODIECU sin grandes costes políticos. Esto explica por qué el Estado aceptó la propuesta de la ONCE y, eventualmente, cómo la ONCE fue capaz de transformar la peor experiencia de su historia (7.000 minusválidos vendiendo una lotería rival) en una excelente oportunidad para refrendar su situación privilegiada en el área de las minusvalías.

\section{LA EXPANSION DEL CORPORATISMO EN EL AREA DE LAS MINUSVALIAS Y LA CREACION DE UN NUEVO SISTEMA DE REPRESENTACION DE INTERESES}

Como resultado de la combinación de esfuerzos entre la ONCE y el Estado para desarticular definitivamente la lotería de los minusválidos, el acuerdo corporatista original entre estos dos actores se ha extendido, configurándose una nueva división del trabajo entre la ONCE y el Estado. De este modo, mientras que el Estado sigue siendo único responsable de determinados programas de bienestar (como los programas de rehabilitación médica, de educación básica, o el pago de subsidios y pensiones de invalidez), la ONCE ha asumido nuevas responsabilidades públicas que afectan ya no sólo a los ciegos, sino al conjunto de la población minusválida, y que se refieren a las políticas de supresión de barreras arquitectónicas y programas de empleo.

Con el fin de llevar adelante sus nuevas responsabilidades públicas, la ONCE creó la Fundación ONCE, cumpliendo su parte del acuerdo de crear un Fondo de Solidaridad con los Minusválidos a cambio del desmantelamiento de PRODIECU. De esta forma, algunos de los programas que antes estaban 
diseñados y financiados por el Estado, lo están ahora por la ONCE y otras organizaciones de minusválidos representadas en el Consejo del Patronato de la Fundación ONCE, como las organizaciones de los minusválidos físicos (COCEMFE, antes CEMFE), de los sordos (CNSE) y de representantes de los minusválidos psíquicos (FIAPAS).

Estas organizaciones, ciertamente, participan en el proceso de toma de decisiones de la Fundación. De hecho, parece existir un alto grado de colaboración entre estas organizaciones y la de los ciegos. Y esto no es de extrañar, dada la generosidad de la ONCE a la hora de financiar los programas de la Fundación. Como resultado de esta colaboración, la Fundación creó más de mil puestos de trabajo para minusválidos durante su primer año de gestión, una cifra muy superior a la de los 300 puestos públicos que la Administración creó durante los tres años anteriores a la puesta en marcha de la Fundación ONCE.

Sin embargo, el hecho de que estas organizaciones dependan de los recursos de la ONCE para satisfacer las demandas de sus afiliados las coloca en una situación totalmente subordinada con respecto a la organización de los ciegos, que, de este modo, está en condiciones de controlar las demandas de estos otros grupos de minusválidos. Este control puede ser laxo o inexistente para aquellas demandas que no ponen en cuestión la posición privilegiada de los ciegos, pero es muy explícito y estricto para aquellas otras que sí lo hacen. Así, de los 25 vocales que componen el Patronato de la Fundación, 13 están reservados para representantes de la ONCE (art. 16), por lo que queda garantizado que el Patronato nunca tomará decisiones que puedan perjudicar a los ciegos. Además, en contra de lo que en un principio se había pensado, el Estado no tiene vocal nato en la Fundación. Para garantizar más, si cabe, el control de las demandas de las asociaciones de otros colectivos de minusválidos, se prevé que «la Fundación no podrá accionar, actuar o plantear reivindicaciones en contra de la persona jurídica del Fundador [esto es, en contra de la ONCE] y de sus legítimos intereses, ya sea de forma directa o indirecta, pública o privada" (art. 4.3). Y como uno de los intereses prioritarios del fundador es conservar, frente a otros colectivos de minusválidos, el privilegio único de explotar una lotería, entre las actividades comerciales que la Fundación pudiera emprender, quedan «expresamente excluidas las relacionadas con el mercado de los juegos de azar» - art. 10.e)—. En resumen, la ONCE ha asumido nuevas responsabilidades públicas en el área política de las minusvalías, extendiendo de esta forma un acuerdo corporatista (que antes afectaba a un segmento de esta población) sobre todo ese área, y ha creado un nuevo sistema de representación de intereses con capacidad para controlar las demandas de otras organizaciones que operan en el mismo área. 


\section{CONCLUSIONES}

Este artículo ha tratado sobre el tema del corporatismo en el área del bienestar. Este es un tema de investigación marginado por la literatura dedicada al estudio de las políticas de regulación y de los grupos de interés, ya que desde esta literatura se suele contemplar el corporatismo únicamente en el ámbito de las políticas económicas y de las relaciones industriales.

Con respecto al área de las políticas de bienestar, la literatura mantiene que o bien los acuerdos corporatistas no tienen lugar en este área o, en caso de surgir acuerdos de este tipo, éstos están promovidos por organizaciones de profesionales proveedores de bienestar. Este artículo ofrece evidencia suficiente para, al menos, cualificar estas predicciones, ya que ha mostrado cómo una red de organizaciones de consumidores (y no una organización profesional) promocionó un acuerdo corporatista en un Estado autoritario; un acuerdo que ha mostrado ser extraordinariamente estable o resistente, ya que no sólo ha sobrevivido al período autoritario, sino que también ha mostrado tener una lógica expansiva, pues si bien en un principio se pensó que este acuerdo corporatista sólo afectaría a un segmento de los minusválidos, el resultado ha sido que toda la población minusválida ha quedado afectada por un acuerdo de este tipo en cuanto a la satisfacción de parte de sus demandas y a la definición de sus intereses.

La estabilidad o consistencia del acuerdo corporatista descrito en este artículo se explica por la relación de interdependencia en que las dos partes del acuerdo están envueltas. En la medida en que el Estado (ya sea autoritario o democrático) considere que es responsabilidad suya garantizar el bienestar de un segmento de la población, dependerá de la organización que representa a esta población, a la que garantiza el monopolio de la provisión de bienestar a sus miembros (siempre que, por supuesto, el Estado no considere posible o deseable, por las razones que sean, proveer bienestar directamente). Por su parte, la organización depende del Estado, en cuanto que es a éste a quien corresponde refrendar o retirar su status público como organización que monopoliza la representación de los intereses de sus miembros y la provisión de servicios a los mismos ${ }^{14}$.

Sin embargo, en la medida en que el Estado considere su interés mantener esta relación de interdependencia (ya porque no pueda o no quiera proveer directamente los servicios de bienestar que la organización está proveyendo), la organización disfruta de una fuente de poder que puede ser empleada siempre que un tercer actor amenace con trastornar su relación privilegiada con el Estado. En el caso que se ha analizado aquí, la solución a esta amenaza ha resultado

14 Sobre las relaciones de interdependencia entre el Estado y organizaciones privadas proveedoras de bienestar, véanse Kramer (1989) y Kuhnle y Selle (1992). Sobre relaciones de interdependencia entre organizaciones, véanse Emerson (1962), Jacobs (1974) y Mindlin y Aldrich (1975). 
en la extensión del acuerdo corporatista, según la cual la organización de ciegos ha asumido nuevas responsabilidades públicas que ya no afectan sólo a los ciegos, sino al conjunto de la población minusválida. Siguiendo la lógica de la relación de interdependencia entre el Estado y la ONCE, se podría argüir aquí que este resultado ha reforzado la situación de dependencia del Estado con respecto a la organización de ciegos, ya que ahora éste depende de la organización no sólo en cuanto a la provisión de servicios para los ciegos, sino también en cuanto a la provisión de otros servicios al resto de la población minusválida.

El argumento de la interdependencia entre el Estado y la organización debe servir para emitir proposiciones más serenas y menos sensacionalistas sobre el carácter de la relación entre el uno y la otra. Durante el transcurso del asunto PRODIECU se acusó a la organización de ciegos de ser una suerte de brazo armado del partido en el gobierno. Con respecto a los ciegos, este tipo de acusaciones no son nada novedosas. Ya en 1835, el liberal Olózaga, intentando explicarse cómo el gremio de ciegos de Madrid había conseguido mantener su monopolio de la venta de diarios y panfletos, reflexionaba de esta manera:

«No se comprende qué secreta relación puede haber entre el partido estúpido y retrógrado que ha dominado en España por espacio de diez años, y estos infelices condenados a eterna oscuridad, [aunque parece probada] la protección decidida que en este tiempo ha dispensado a los ciegos la extinguida Sala de Alcaldes» (Olózaga, 1835: 17).

La organización de ciegos puede flirtear con el gobierno de turno a fin de procurarse las mayores garantías de que sus intereses serán respetados. Pero, como se ha argumentado aquí, la base del poder real de la ONCE no descansa en el tipo de contactos, a veces afortunados, otras tormentosos, que los ciegos puedan mantener con el gobierno de turno, sino en el hecho de que la organización conserva, frente al Estado, el monopolio de la provisión de servicios de bienestar para los ciegos. Y este monopolio le sirve ante cualquier color del gobierno, sea socialista o conservador. O, como cuenta Ferrer, absolutista o liberal, pues, antes que la ONCE, el gremio de ciegos de Madrid del siglo XIX

«se amolda a las circunstancias como un diplomático de primera tijera, y con todos come y de todos saca astilla» (Ferrer, 1851: 372). 


\section{REFERENCIAS}

Cawson, A. (1982): Corporatism and Welfare State: Social Policy and State Intervention in Britain, Londres: Heinemann Educational Books.

- (1986): Corporatism and Political Theory, Londres: Basil Blackwell.

Díaz Casanova, M. (1985): El asociacionismo de los minusválidos. Entre organización y movimiento social, Madrid: Ministerio de Trabajo y Seguridad Social.

EMERSON, R. M. (1963): "Power-dependence Relations», en American Journal of Sociology, 69, pp. 32-40.

FERrER, A. (1851): «El Ciego», en AA.VV., Los españoles pintados por sí mismos, Madrid: Gaspar y Roig Editores.

Gambling in the Single Market. A Study of the Current Legal and Market Situation, 3 vols., Commission of the European Communities, 1992.

GARVÍA, R. (1992): La organización nacional de ciegos. Un estudio institucional, Madrid: Instituto Juan March de Estudios e Investigaciones, CEACS, vol. 2.

- (1994): "Revisiting Rationality in Organizations», Center for European Studies, Harvard University, Working Papers Series, n.o 55.

GuiraO, J. (1985): «Gambling in Spain: The Unplanned Revolution», en William R. Eadington (ed.), The Gambling Studies. Proceedings of the Sixth National Conference on Gambling and Risk Taking, College of Business Administration, University of Nevada, Reno.

Hahn, H. (1988): "The Politics of Physical Differences: Disability and Discrimination», en Journal of Social Issues, 44, pp. 159-172.

HALDRICH, H. (1973): «Organizational Boundaries and Interorganizational Conflict», en F. Baker (ed.), Organizational Systems, Homewood: Irving-Dorsey.

INSERSO (1989): Las personas con minusvalía en España, 2 vols., Madrid: Ministerio de Asuntos Sociales.

JaCOBS, D. (1974): «Dependency and Vulnerability: An Exchange Approach to the Control of Organizations», en Administrative Science Quarterly, 19, pp. 45-59.

Jordana DE POZAS, J. (1967): «El movimiento asociativo y la asistencia social», en Problemas fundamentales de beneficencia y asistencia social, Madrid: Ministerio de Gobernación.

Kramer, R. M. (1989): "The Use of Governmental Funds by Voluntary Social Service Agencies in Four Welfare States", en E. James (ed.), The Nonprofit Sector in International Perspective. Studies in Comparative Culture and Policy, New York, N.Y.: Oxford University Press.

Kuhnle, S., y Selle, P. (1992): Government and Voluntary Organizations: A Relational Perspective, Londres: Gower.

Lehmbruch, G. (1977): «Liberal Corporatism and Party Government», en Comparative Political Studies, 10, pp. 91-126.

LowI, T. (1979): The End of Liberalism, 2. ${ }^{\text {e }}$ d., New York: Norton.

Mindlin, S. E., y Aldrich, H. (1975): «Interorganizational Dependence: A Review of the Concept and a Reexamination of the Findings of the Aston Group", en Administrative Science Quarterly, 20, pp. 382-392.

Olson, M. (1965): The Logic of Collective Action, Cambridge, Mass.: Harvard University Press.

Olózaga, S. (1835): Informe sobre las ordenanzas de la Hermandad de los Ciegos de esta Corte, leido en la Sociedad Económica Matritense por el socio Don Salustiano de Olózaga, Madrid: Imprenta del Colegio de Sordomudos.

ONCE (1986): I Jornadas de Relaciones Públicas y Comunicación de la ONCE, Madrid, 14 y 15 de octubre de 1986, Madrid: ONCE.

SChmitTer, P. C. (1979): «Still the Century of Corporatism?», en P. C. Schmitter y G. Lehmbruch (eds.), Trends Towards Corporatist Intermediation, London: Sage.

- (1985): «Neo-corporatism and the State», en Wyn Grant (ed.), The Political Economy of Corporatism, New York, N.Y.: Saint Martin's Press.

ScOTCH, R. K. (1988): «Disability as the Basis for a Social Movement. Advocacy and the Politics of Definition", en Journal of Social Issues, 44, pp. 159-172.

Suleiman, E. N. (1987): "State Structures and Clientelism: The French State Versus the "Notaires"”, en British Journal of Political Science, 17, pp. 257-279. 


\title{
RESUMEN
}

La literatura sobre corporatismo ha señalado la escasa probabilidad de que surjan acuerdos de tipo corporatista en el ámbito del bienestar. Esta literatura ha anticipado que, en caso de emerger un acuerdo de este tipo en el ámbito del bienestar, este acuerdo será promovido por organizaciones profesionales que operan en este ámbito. En contra de esta predicción, este artículo analiza un caso desviado, que hace referencia a la organización de ciegos españoles (ONCE), que monopoliza la representación de intereses de los ciegos y la provisión de servicios de bienestar a los mismos. El artículo examina brevemente la naturaleza del acuerdo corporatista que tiene lugar entre el Estado y la ONCE, y explica cómo este acuerdo, limitado originariamente al caso de los ciegos, se ha expandido sobre el conjunto del área de las minusvalías, de tal modo que la ONCE ha conseguido no sólo controlar y gobernar el sistema de representación de intereses de otros grupos de minusválidos, sino también asumir políticas públicas que afectan a estos otros colectivos. Se argumenta aquí que esta expansión del corporatismo sobre el conjunto del área de las minusvalías se explica por la relación de interdependencia en que el Estado y la organización de ciegos están envueltos.

\begin{abstract}
The literature on corporatism has pointed out that corporatist arrangements are unlikely to occur in the welfare arena. It has been predicted that for a corporatism arrangement to emerge in the welfare arena, it will be promoted by professional groups. Contrary to these predictions, this paper analyses a deviant case, that of a corporatism arrangement promoted by welfare recipients, in this case, the Spanish blind. The paper briefly examines the nature of this corporatism arrangement, carried out by the State in conjunction with ONCE, the Spanish organization of the blind which monopolizes both the representation of the interests of and the provision of welfare services for the blind. The paper shows how this limited corporatism arrangement which formerly only affected the blind, has expanded over the whole disabilities policy arena, in such a way that the blind have managed both to govern the representation of interests of other organizations of disabled people and to take over public policies affecting these other groups of disabled. This expansion of a formerly limited corporatist arrangement is explained by the kind of the interdependent relationship in which the State and ONCE are involved.
\end{abstract}

